\title{
Rasgos do Urbano: Imagens em Deriva
}

\section{Urban Ruptures: Images Adrift}

Resumo: Esse texto se propõe a problematizar o uso da imagem deslocando-a de seu lugar costumeiro de representação do mundo, para pensar sua potencia de criação do real. Para isso utilizamos cinco imagens produzidas pelo grupo Ghawazee Coletivo de Ação a partir de performances em intervenção urbana e duas imagens, disponibilizadas pelo grupo, que foram utilizadas como material de pesquisa no processo criativo destas ações. Essas imagens trazem o potencial de mobilizador dos signos pré-definidos da cidade, das práticas cotidianas e dos corpos que ocupam espaços urbanos, colocando o espectador das imagens em um estado de deriva ao considerar estas como ilhas desertas criadas em uma prática cognitiva vinculada à invenção de si e do mundo, agenciando uma educação que se processa por experimentação, aliando o pensamento ao caos, empreendendo uma prática conectada à imprevisibilidade e ao inesperado de signos em deslocamentos e em busca de novos sentidos.

Palavras-chave: Imagens. Experimentação. Educação. Urbano.

Abstract: This text proposes to problematize the use of the image by moving it from its customary place of representation of the world, to think its real creation power. For this we use five images produced by the Collective Action of Ghawazee group from performances in urban intervention and two images, provided by the group, which were used as research material in the creative process of these actions. These images bring the potential of predefined signs mobilizer of the city, the daily practices and bodies that occupy urban spaces, putting the viewer of the images in a state of drift when considering these as deserted Islands created in a cognitive practice linked to the invention of the self and the world, promoting an education that processes itself by experimentation, combining the thought to chaos, undertaking a practice connected to unpredictability and the unexpectedness of signs in dislocations and in search of new senses.

Keywords: Images. Experimentation. Education. Urban.

BOM-TEMPO, Juliana Soares. Rasgos do Urbano: imagens em deriva. Informática na Educação: teoria e prática, Porto Alegre, v. 17, n. 1 , p. $61-76$, jan./jun. 2014

\section{Juliana Soares Bom-Tempo \\ Universidade Estadual de Campinas}

"Não mais representar o visível, mas tornar visível." Paul Klee
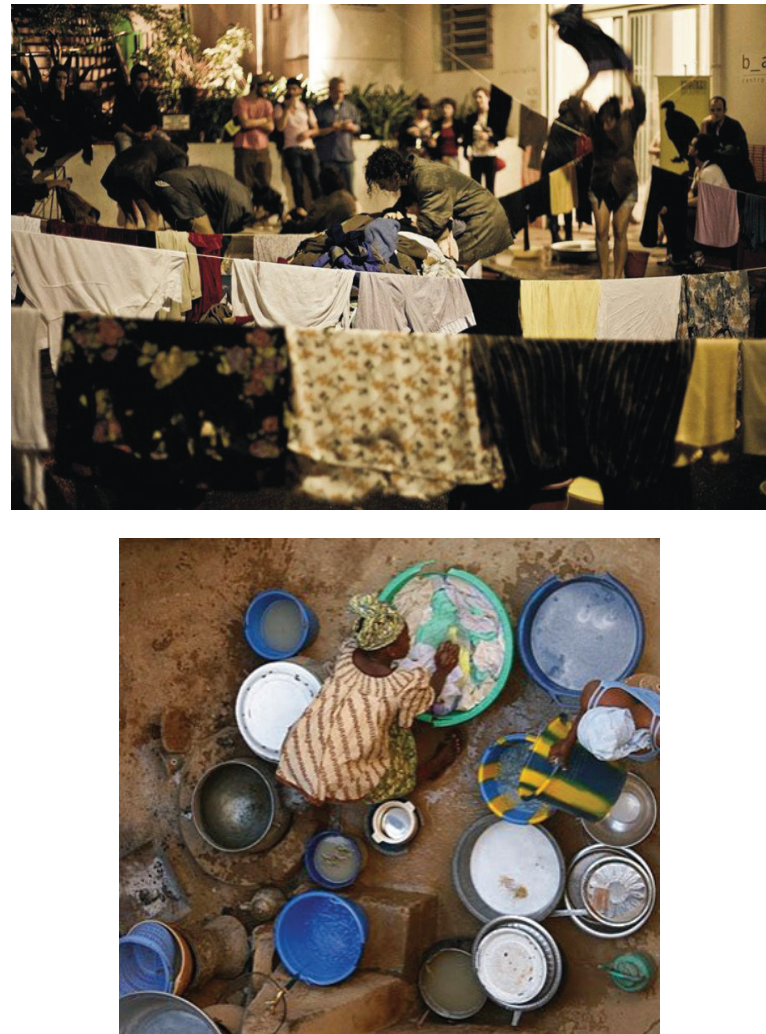

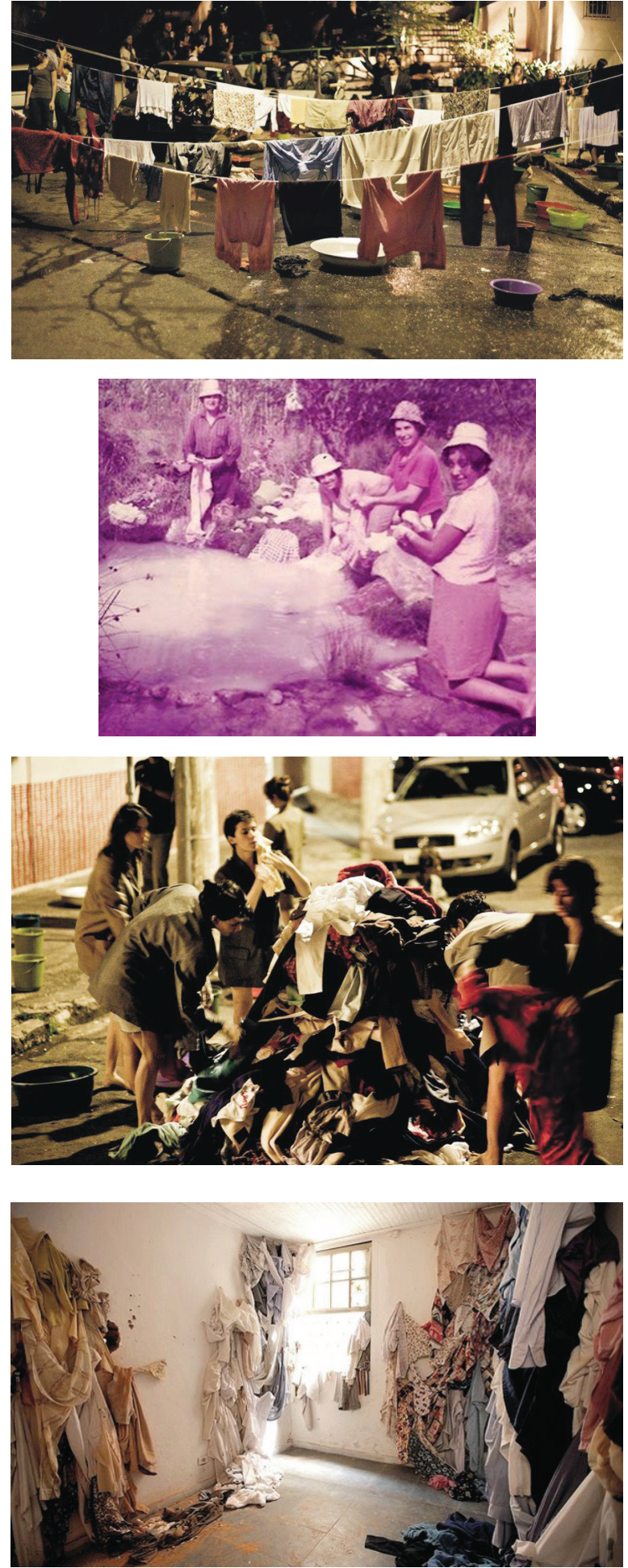

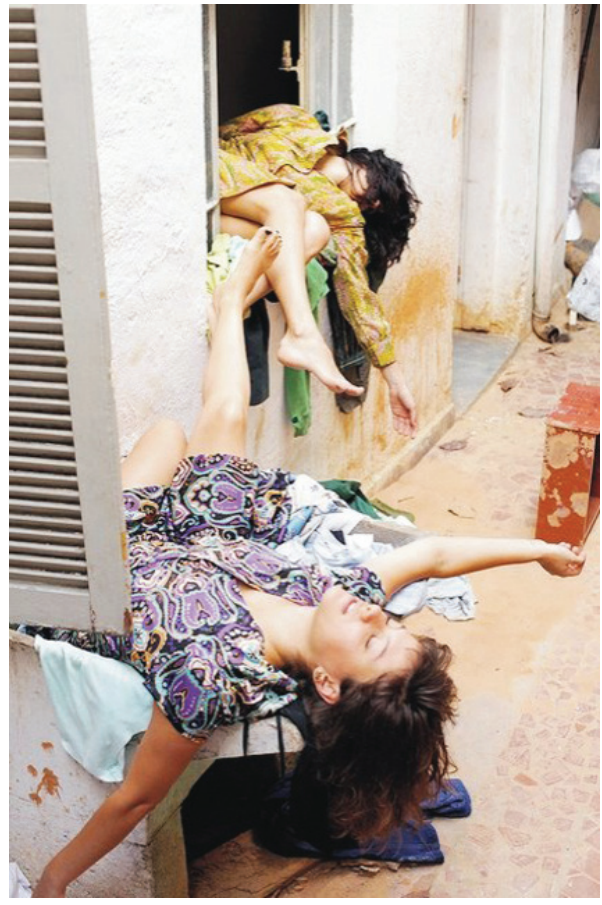

\section{Imagens-cidade}

D) oupas em varais interditam cotidianos urbanos, produzem cortes nas ruas e nos olhares. Choques. Cotidiano dissolvido na paisagem, como aquilo que não se percebe mais, misturado ao contexto e dissimulado no entorno, confundindo-se com aquilo que o envolve: exposição em vias públicas de intimidades escondidas. Em público se lavam roupas.

Fissuras do urbano, da intimidade, de muIheres, de roupas lavadas que enchem a cidade, misturam tempos, invadem espaços de concreto, enchem bacias, pigmentam com múltiplas texturas e cores o cimento que esquadrinha o cotidiano.

Ação de lavar roupas, comum como uma coisa qualquer, uma coisa que não se destaca, quase imperceptível. Cotidiano dissolvido na paisagem, aquilo que não se percebe mais, 
camuflado (uma mimese, uma imitação) naquilo que está no entorno, escape de forças ocultas, em intimidades que se explicitam na rua pública.

O cotidiano "[...] no seu aspecto fastidioso, penoso e sórdido (o amorfo, o estagnante), e o cotidiano inesgotável, irrecusável e sempre inacabado, sempre escapando às formas" (BLANCHOT, 2007, p. 237) 1 .

Imagens provocam uma escrita e colocam a cidade em deriva. As imagens dispostas acima são ângulos, perspectivas, luz e sombras de performances em intervenções urbanas feitas pelo grupo Ghawazee Coletivo de Ação. Esse coletivo, composto por 10 mulheres com diferentes formações artísticas, busca criar um espaço de experimentação de linguagem propondo rupturas temporárias na ordem do cotidiano, dirigindo-se principalmente ao público local e passante, sem a necessidade de formar uma audiência previamente. Assim, atuam com intervenções no espaço da cidade. ${ }^{2}$

Trataremos por bloco um (1) a composição das três primeiras imagens à esquerda; tais imagens criam um novo plano de experimentação que mobiliza o modo de estar na cidade. Este bloco ganha a funcionalidade de analisador ao explicitar as dinâmicas de intimidades que habitam a cidade em práticas cotidianas escondidas nas separações entre o que é pró-

\footnotetext{
${ }^{1}$ BLANCHOT, M. A fala cotidiana. In: BLANCHOT, M. A conversa infinita 2: a experiência limite. São Paulo: Escuta, 2007. ${ }^{2}$ As principais ações do coletivo acontecem em São Paulo, com algumas ações pontuais em outras cidades tais como Bogotá na Colômbia, Córdoba na Argentina e Villa Alegre no Chile. O grupo possui 13 ações já executadas em contextos variados da cidade de São Paulo. "Nas vilas egípcias uma dançarina profissional é conhecida como ghaziya (plural ghawazee). As ghawazee originais eram ciganas, ainda que a palavra tenha se tornado um termo genérico para dançarinas ao invés de denotar uma ou várias tribos em particular, como era o caso. [...]. Em egípcio ghawazee significa "invasores" ou "marginais", e os ciganos sempre viveram de fato ao redor das cidades e as margens da sociedade." Wendy Buonaventura, The serpent of the Nile. Disponíveis em: http://ghawazee.wordpress.com/acoes/acao-9/galeria-gallery- $9 /$.
}

prio do plano íntimo e o que é do contexto público, produzindo problemas para as formas de viver na cidade e na intimidade. Sujeiras íntimas agora lavadas em público, em imagens que empilham, penduram, escorrem, batem roupas, criando rasgos, brechas, fissuras para pensar e fazer problemas frente ao que é possível e desejável para os modos de estar nas ruas.

Por bloco dois (2), traremos as duas imagens à direita, imagens que servem como material, matéria prima para o processo criativo Ghawazee. O coletivo empreende no processo criativo uma pesquisa de imagens relacionadas à proposta da ação. Buscam agenciamentos, conexões, vínculos que possibilitem uma ação performativa. Duas imagens: a primeira em cores vivas, texturas de baldes, águas e roupas que colorem a textura ocre da terra, duas mulheres negras, uma de cócoras para esfregar, outra providenciando mais água; a segunda traz o envelhecer da imagem, criado pela câmera ou pelo tempo? Pose para foto, práticas de mulheres cotidianas a lavar roupas sujas que podem ser antigas ou recentes, imagens que falam de mulheres que ainda hoje lavam roupas. Mulheres de outros tempos, outros espaços, lavam publicamente as sujeiras íntimas de roupas usadas em rastros de afetos que turvam a água.

O bloco três (3), composto pelas últimas duas imagens, problematiza intimidades: corpos vestidos, jogados em janelas e tanques, roupas instaladas a subir paredes. Corpos entram em mistura com a condição de roupas jogadas, espalhadas, sujas, roupas-corpos por lavar, imagens que criam paisagens de intimidades precárias, espalhadas. Casa vazia preenchida por roupas que sobem paredes e anunciam um fora pela luz estourada a invadir o cômodo pela janela. Um fora que convoca a 
primeira imagem a escorrer para a segunda. Segunda imagem: um lado de fora que anuncia um dentro por corpos-mulheres vestidos deixados nas janelas, corpos-roupas femininos espalhados, abandonados. Sombras colorem a janela e convidam para um dentro fazendo a segunda imagem deslizar para a primeira.

Espaços em risco, espaços íntimos e urbanos produzindo, na precariedade cotidiana de vidas limitadas ao já dado e já esperado, tensionamentos e problematizações interessantes $^{3}$ que mobilizam cidade, ruas, casa, roupas e corpos, abrindo outros processos de subjetivações.

Guattari (1992) propõe um novo pensamento sobre a espacialidade no contexto urbano, suas relações com a corporeidade e com os processos de subjetivação, articulando-se à proposta presente nas imagens iniciais deste texto. Particularmente, em um dos capítulos do livro Caosmose, intitulado "Espaço e Corporeidade", o autor apresenta que as dinâmicas urbanas de trânsito, os fluxos de conexão dos corpos aos automóveis, a arquitetura dos prédios, as disposições das ruas atuam diretamente nas configurações corpóreas e nos modos de estar na cidade.

Assim, ao dirigir um automóvel, acontece uma atração espacial que privilegia a atenção frontal, deixando submetido às outras dimensões corpóreas, como os membros que ficam subjugados à máquina automobilística e às sinalizações das ruas, avenidas e estradas. Diante desses aspectos, há várias camadas sobrepostas que coexistem em espaços heterogêneos, podendo agenciar pontos de fuga da

\footnotetext{
3 Ao considerarmos as problematizações aqui propostas "interessantes", estas não estão simplesmente no registro das adjetivações. Tratamos tais proposições não como verdadeiras ou falsas, mas como interessantes para forçar o pensamento, como proposto por Gilles Deleuze (1992, p. 162). "As noções de importância, de necessidade, de interesse são mil vezes mais determinantes que a noção de verdade."
}

circulação preestabelecida no trânsito de veículos e criar espaços de lembranças, de imaginação, ou mesmo espaços artísticos.

Outras conexões com a cidade são produzidas nos encontros com paisagens que correm o risco de ganhar atributos estéticos, gerando composições afetivas e éticas, colocando problemas à estratificação espacial da cidade. Novas paisagens urbanas são configuradas pelas imagens produzidas frente às ações do Ghawazee, que abrem outras relações com o urbano ao deslocarem práticas íntimas para o espaço da cidade e ao criarem imagens de corpos-roupas invadindo e deixados numa casa. Outras subjetivações são geradas a partir das imagens, entrando em relações com um cotidiano cheio de brechas para alguns escapes às formalizações.

O autor Guattari (1992) traz ainda outro exemplo: as percepções dos espaços na atualidade que podem se desdobrar em percepções antigas, sendo esse processo de recordação acompanhado por afecções presentes, criando novas impressões de forma inventiva. As imagens do Ghawazee em ações, inspiradas em outras imagens de espaços e de tempos distintos, são colocadas lado a lado, agenciam memórias ${ }^{4}$ e produzem sensações presentes, produzindo variações nas impressões do urbano e de casas habitáveis.

Os blocos de imagens, ao serem colocados juntos, produzem uma intervenção ao trazer a público algo que é feito de forma privada. Os signos mobilizados por tais imagens provocam deslocamentos dos sentidos de lavar roupas, de estar nas ruas, dos modos de habitar uma casa. Corpos abandonados povoam casas. Va-

\footnotetext{
${ }^{4}$ A memória é entendida no sentido de considerá-la um processo de busca cognitiva por experiências passadas que se atualizam no momento presente, estabelecendo uma relação co-dependente entre passado e presente que configuram o real em estados atuais e virtuais (BERGSON, 2011).
} 
rais interditam ruas, roupas escorrem tingindo o asfalto. Rasgos no cotidiano, rasgos no urbano.

Mesmo que não haja consciência, "o espaço construído nos interpela de diferentes pontos de vista: estilístico, histórico, funcional, afetivo..." (GUATTARI, 1992, p. 157). A arquitetura da cidade, com seus prédios e construções tem a potência de "máquinas enunciadoras" que produzem subjetividades abertas a conexões com outros processos de subjetivação vinculados à cognição e aos afetos.

Os espaços construídos produzem efeitos além do que vemos e de como funcionam usualmente na cidade. "São essencialmente máquinas, máquinas de sentido, de sensação" (GUATTARI, 1992, p. 158). As configurações urbanas, os objetos presentes na cidade, as arquiteturas têm a potencialidade de funcionarem tanto como efeitos de universalização e homogeneização, como de liberações de processos de singularização coletivos e individuais, estando articulados ao que se produz nos encontros.

Os corpos e espaços construídos nas imagens interagem produzindo existências efetivas e potenciais em zonas heterogêneas e caóticas. Há um agenciamento de conexões com a cidade em uma variação entre os signos urbanos e as maquinações produzidas pelas imagens que mobilizam os signos da cidade, do feminino, das intimidades e das relações.

Mulheres em roupas masculinas, paradas em gestos que anunciam a ação: batem a roupa, esfregam-na, penduram-na; roupas escorrem, mancham a rua, interditam vias em varais e amontoadas (bloco 1 ). Mulheres lavam roupas, esfregam-nas, colorem a terra, em meios campestres posam para foto; as imagens anunciam outros tempos e outros espaços a produzir dobras em mulheres atuais e urbanas (bloco 2). Corpos-roupas de mulheres jogados, esparramados, sobem as paredes, deixadas nas janelas, janelas que são transições de dentro e de fora da casa, do corpo, da roupa. Rasgam o urbano em intimidades abandonadas (bloco3).

Vidas em risco (bloco $1+$ bloco $2+$ bloco3). Signos em variações: 0 que pertence ao urbano e o que é próprio da vida íntima? Seria essa separação uma máquina de enunciação politicamente construída com argamassa e concreto de rígidas significações?

Guattari (1992) amplia o conceito de máquina ao ligá-lo às dimensões desejantes, articuladas a aspectos econômicos, políticos, históricos, ecológicos. Engrenagens urbanísticas que ganham efeito de iniciarem processos de subjetivação em sistemas autopoiéticos ${ }^{5}$, diferentes de sistemas de significações estruturais. Nessa perspectiva, as imagens conectam-se com o que é próprio e o que é improvável no contexto urbano, ligam-se a jogos de sensação que nos levam a campos ainda não habitados na cidade, fazem a cidade entrar em processos não usuais, produzindo singularizações em novas imagens urbanas.

Guattari (1992) propõe um deslocamento da subjetividade para os componentes materiais enquanto subjetividades parciais, "a cidade, a rua, o prédio, a porta, o corredor... modelizam, cada um por sua parte e em composições globais, focos de subjetivação". (p. 161). Os espaços construídos, as dinâmicas urbanas, a intervenção performática estão associados e possuem sentidos a-significantes vertendo-se em imagens, criando componentes sempre parciais e heterogêneos de subjetivação.

O autor aponta para uma redefinição das ligações de espaços construídos e dos processos de subjetivação, colocando-nos as dimensões

\footnotetext{
$\overline{5}$ Termo cunhado por Francisco Varela que designa os processos autocriativos presentes na natureza e que Guattari utiliza para conceituar as "máquinas desejantes".
} 
políticas presentes nas imagens, na cidade, nas produções de corporeidades e de subjetividades (GUATTARI, 1992). As imagens Ghawazee previamente dispostas interferem no cotidiano dos signos costumeiros e rotinizados de como é organizada a cidade e produzem escapes às formalizações ao apresentarem composições imagéticas não próprias da rua, do trânsito, da forma de se estar com roupas em uma casa ou de lavar-bater roupas sujas na rua.

As imagens se configuram nos interstícios dos corpos, das ruas, da casa, da ação e das roupas, ganham funções de linhas que capturam um momento escorregadio da própria imagem aderindo-se a dimensões que saltam à textura bidimensional da fotografia e invadem o real. Criam composições e trazem a potência maquínica de enunciação coletiva, máquinas capazes de relacionar e conectar enunciados ao produzirem imagens que não se apresentam como real representado. Essas imagens-máquinas ${ }^{6}$ configuram-se como formas hiperadensadas da própria subjetividade, sendo que elas mesmas subjetivam, desbancando hierarquias e produzindo relações transversais entre corpos, cidades, imagens e objetos.

Nelson Brissac Peixoto (1993) escreve sobre as imagens construídas na passagem, no entre, na intersecção. A passagem na intervenção urbana ganha "lugar de composição das imagens" (p. 237). A arquitetura e o urbanismo entram em composição com outras artes como a performance, a intervenção urbana, a instalação e a fotografia, criando imagens que inventam por sua vez um real. É nesse cruzamento, nesse encontro que a paisagem contemporânea se apresenta, configurando-se como lugar de passagem.

\footnotetext{
${ }^{6}$ Referência ao título do livro organizado por André Parente (1993) Imagem Máquina - a era das tecnologias do virtual, Editora 34, Rio de Janeiro.
}

Há nas imagens apresentadas a criação de um território formado por passagens, por "entre-lugares" que possuem uma permeabilidade de interações. O olhar toca, em uma prática de tateio, o que acontece ali, em uma composição entre o que se vê e o que se sente na pele, construindo, assim, uma nova visibilidade de texturas nas imagens. Dessa forma, constitui-se um tecido, uma malha entre o que é visível e aquele que vê, em um campo de troca recíproca. É nesse encontro, nesse entre que se constitui a imagem, como um espelho em frente ao outro, criando camadas de imagens que se adensam em dobras (PEIXOTO, 1993).

Ao apresentarmos as imagens em blocos que se misturam, ampliamos as suas perspectivas, fazendo uma foto se alinhavar à outra, à próxima e à lateral, ampliando sentidos que tentam fixá-las em uma narrativa que responderia ao: o que é isto? Tensionamentos são colocados em texturas presentes nas imagens: cores, corpos, luzes, sombras, dias e noites. Conversações são produzidas e colocam as próprias imagens em derivas.

Segundo Peixoto (1993), a paisagem é esse campo espacial adensado em uma visibilidade sem nome, sem sujeito, em uma zona de convergência de forças que ele chama de "intercorporal" (p. 238), zona que ganha visibilidade no entre, no meio das coisas. Entre-lugares que compõem um plano de experimentação ao aproximarmos blocos de imagens, fazendo variar signos e sentidos daquilo que é próprio à rua, aos corpos, às roupas, à casa, às mulheres, às intimidades.

Deleuze (1998, p. 71) destaca a junção "e" para designar essa zona de encontro ao estar no meio, no entre. Mover-se entre as coisas, produzindo conexões entre pontos quaisquer, entre coisas, sem começo, sem fim. Um "en- 
tre-lugares" em que algo acontece entre os componentes, uma mistura de atributos e traços, irredutível aos componentes iniciais. Assim, as imagens apresentadas se constituem como uma conjunção que têm a potência da diferença em um adensamento que mantém os heterogêneos e se instaura como novo agenciamento de forças.

\section{Imagens em processos educati- vos}

Essas imagens, ao desviarem signos pré-estabelecidos, agenciariam processos de aprendizagem? Como essas imagens ganham a potência educativa na relação com o urbano?

Deleuze $(1987)^{7}$ produz uma leitura que pode ser instigante para pensar as imagens das ações desse coletivo na relação com a cidade. 0 autor afirma que nunca se sabe como uma pessoa aprende; mas de qualquer forma sempre aprende por meio de signos, perdendo tempo em buscas de uma decifração dos signos; não pelo acúmulo e assimilação de conteúdos materiais objetivos. Esses conteúdos intelectuais são verdades limitadas, pois não são aprendidos por necessidades.

O dia-a-dia na cidade, as rotinas estabelecidas, os caminhos percorridos, o tempo gasto ou perdido no percurso, o ritmo das caminhadas, o que encontramos no caminho, todas essas ações que configuram o urbano encontram-se em relações já estabelecidas como conteúdos objetivos.

Ao nos depararmos com as imagens de muIheres vestidas em ternos executivos lavando montes e montes de roupas na rua, tornando pública uma ação extremamente íntima que

\footnotetext{
7 Proust e os signos, de Gilles Deleuze (1987). DELEUZE, Gilles. Proust e os signos. Cidade: Ed., 1987.
}

todos nós fazemos, com imagens de roupas a cobrir chão, paredes e teto como se invadissem os cômodos, com imagens de mulheres jogadas ao chão como roupas espalhadas pela casa e a sair pelas janelas, deparamo-nos com imagens que problematizam a rua, a cidade e o cotidiano, colocam outros caminhos no urbano e nos modos de existir nas relações diárias com as roupas, com os corpos, com as ruas e com o lavar roupas sujas. Saem da rotina e desestabilizam signos rígidos levando a experiência urbana à errância nas imagens, imagens que apresentam texturas, perspectivas, luminosidades que precipitam estranhamentos e deslocamentos.

Silvia Duschatzky (2007) afirma que a errância não se sujeita a um território institucional, mas coloca as instituições em um novo solo ao problematizar saberes rígidos e preestabelecidos que, no dia-a-dia, pouco se mobilizam diante das demandas do presente. ${ }^{8}$ Tais saberes localizam a educação em organizações escolares e buscam fixar as práticas educativas nesses territórios. Este artigo pensa a educação aliada às forças vitais, à construção dos modos de vida e de práticas empreendidas que trazem a urgência de entrarem em errâncias que mobilizem a cidade, as intimidades, o feminino. Práticas educativas presentes nas imagens ao colocarem essa errância nos signos que tentam fixar os sentidos, as coisas, as subjetivações, o urbano.

As imagens performativas, ao interferirem nos signos urbanos, funcionam como analisador da cidade e explicitam pistas de novos caminhos, a experimentação e a invenção de outros modos de existência, tendo como potencialidade o colocar-se no mundo de outras

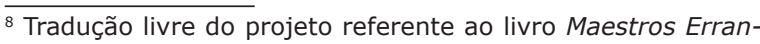
tes: experimentaciones sociales en la intempérie, Buenos Aires: Paidós, 2007.
} 
maneiras, que não estão postas ou sugeridas, mas que demandam práticas inventivas.

O aprendizado não está nem no passado e nem na memória como conteúdos, mas se direciona a um processo de busca. O importante nesta empreitada é o que não se sabe a princípio. Não há início nem fim. Aprende-se progressivamente, com decifrações, decepções sofridas e ilusões perdidas. Não há linearidade, ora há recuos, regressões e preguiça. Processo frágil de abertura do aprendiz para se sensibilizar aos signos em busca de sentidos sempre provisórios (DELEUZE, 1987). As imagens apresentadas nos trazem relações com contextos impróprios para as ruas de uma cidade, colocando o pensamento em busca de novas conexões de sentido na relação com os signos urbanos.

Para a ativação deste processo é preciso que haja encontros, os quais promovem desvios, violências que desafiam as crenças e as leis prontas. Acredita-se por crença ou lei que o mundo objetivo traz o signo fixo e sedentário, impossibilitando qualquer desvio, ordenado pelas leis da linguagem. Confunde-se 0 significado do signo com o objeto que ele designa. Superficialidade, aprisionamento do signo e estagnação de aprendizagens que produzem subjetivações e adoecimentos, pois fixam e estabilizam o mundo (DELEUZE, 1987).

Ao considerarmos costumeiramente, em especial no campo da educação, as imagens como documentos que representam o real, quando se toma o real objetivo pelas imagens, colocando-as como representação do mundo, acontecem aprisionamentos dos signos que se tornam, portanto, predefinidos, sedentários e fixos.

Imagens que atravessam os cotidianos em jornais, revistas, facebooks, livros didáticos são tomadas como representantes de um real em si, camuflando toda dimensão política de fixação de certo real desejável para os modos de vida contemporâneos. Seja pelos corpos perfeitos, seja pelas relações de consumo e desejo, nas construções subjetivas de medos, mesmo pelas demonstrações de diferenças sociais pasteurizadas entre ricos e pobres ou nas fixações de hierarquias socioeconômicas presentes nos mapas, há uma relação com as imagens que produzem um real e o sedentarizam como único, em aprendizagens, tanto formais quanto informais, que produzem subjetivações nas relações com os modos de viver, sentir e habitar o mundo.

Há uma produção de modos de abordar as imagens em aprendizagens que se focam no acúmulo de conteúdos já estabelecidos. Por outro lado, Deleuze (1987) diz da aprendizagem enquanto um processo de relembrar, que tem a memória como meio, e, paradoxalmente, está em um movimento de busca direcionado para o futuro. Aprender, nesta perspectiva é interpretar signos e emitir outros signos. Assim, os signos possuem ao mesmo tempo, unidade e pluralidade voltada a movimentos de busca.

Ao deslocar narrativas íntimas de lavar, esfregar e pendurar roupas para o contexto de narrativas urbanas acontece intervenções no sentido de criarem problemas às imagens sedentarizadas do que é o urbano, das práticas de vida próprias deste contexto, dos modos de se estar em uma casa, dos tempos que colocam mulheres no lugar de lavadeiras. Os elementos reconhecíveis nas imagens apresentadas da rua, das roupas, dos corpos, das mulheres, da casa funcionam como mínimos necessários para problematizarem esses signos, colocando-os em movimento e produzindo outros signos, signos inventivos da arte.

Os signos da arte, como prática criativa, atuam nos signos já existentes desmateria- 
lizando-os em sentidos que são construídos de forma temporária. O mundo revelado da arte reage, principalmente, sobre os signos sensíveis, os quais são integrados e ganham sentidos estéticos, invadindo o que havia de vazio. Os signos sensíveis remetem à encarnação em sentido material, mas a arte é a única que tem a potencialidade de compreendê-los e ultrapassar interpretações vindas de signos preconcebidos. Assim, todos os outros signos voltam-se para a arte e, para Deleuze, todos os aprendizados por caminhos mais diferentes, são, inconscientemente, da própria arte. Diante disso, "o essencial está nos signos da arte" (DELEUZE, 1987, p. 14).

A arte, portanto, funciona como um mobilizador de novos sentidos aos signos, problematizações do mundo presentes nas imagens do Ghawazee ao se aliarem as forças dos escapes às formalizações presentes na cidade, potencializam linhas de fuga ${ }^{9}$ das práticas cotidianas sedimentadas nos modos de vida urbanos.

Desta forma, segundo Deleuze (1987), cada signo faz parte de várias dimensões do tempo em busca da verdade. Nesse processo, a busca da verdade está ligada à busca do tempo perdido, em processos de aprendizagens. A verdade, portanto, possui uma relação essencial com o tempo. A verdade, aqui colocada, não se fixa em uma verdade preconcebida e única, mas se vincula à compreensão da verdade como transitória e como uma possível avaliação do mundo.

Só se procura o tempo perdido e a própria verdade quando se é impelido a fazê-lo por alguma situação real. Este processo se dá quando se é violentado a procurar a verdade, se dá por necessidade e não apenas por boa vontade.

\footnotetext{
${ }_{9}^{9}$ Termo de Gilles Deleuze e Félix Guattari (1995) citado em Mil Platôs: capitalismo e esquizofrenia - vol. I. Os autores afirmam que a linha de fuga permite explodir o que está estratificado no interior do próprio processo, fazer vazar o que está organizado e passar a proceder por conexões.
}

Esta violência vivida é a garantia de uma busca que assegura a autenticidade do aprendiz. É através de encontros casuais com signos que esta pressão coercitiva acontece e exerce violência.

Só é possível querer a verdade e buscá-la pela coação, por uma necessidade gerada no encontro com determinado signo. Quer-se encontrar o sentido do signo. Esta busca é sempre temporal e a verdade é um acontecimento engendrado em um tempo múltiplo e plural. Tempo perdido. Essa violência é agenciada pelo embate e combate de forças que operam no e pelo aprendiz nos encontros (DELEUZE, 1987).

Ao nos encontrarmos com as imagens das ações Ghawazee, somos conduzidos a reabitar a cidade e a ocupar o cotidiano vinculado às forças inventivas em busca de sentidos que se atualizam momentaneamente, colocando os signos que tendem a fixar o urbano, os modos de vida, as relações com o feminino em errâncias, criando problemas para as instituições vinculadas a estes signos.

Nessa empreitada de busca, o que se encontra do tempo perdido é outro tempo, diferente deste primeiro, um tempo redescoberto. O tempo perdido é o tempo que se perde, não apenas o tempo que passa. Os signos do mundo e os signos sensíveis são signos do tempo perdido, de um tempo que se perde. O tempo redescoberto é criado e produzido, próprio dos signos da arte, tempo original que compreende todos os outros (DELEUZE, 1987).

Imagens Ghawazee impelem uma busca de signos para a questão: o que está acontecendo ali? Relações composicionais nas sensações de cores, de luminosidade, de contornos, de texturas que criam cidades e instauram tempos. Blocos de imagens colocados para funcionarem juntos, fazendo com que ações de um cotidiano íntimo vazem para a rua e casas, variando os 
modos de serem habitadas, revisitando corpos, mulheres, roupas e os próprios modos de vida, tempos redescobertos dos signos da arte.

Tais imagens disparam intervenções no urbano - no tecido de relações políticas, sociais e econômicas que se expressa fisicamente e subjetivamente - como invenção de um real em uma prática de tateio, de experimentação, de articulações e de deslocamentos inesperados dos signos que entram em choque com a matéria como repetição.

Aprendizagens acontecem nessas tensões entre tempo e matéria, entre tendências criativas e tendências repetitivas. Isso acontece por experimentação com a matéria, envolvendo o tempo. Os efeitos dessas ações não são instantâneos e imediatos. Assim, nunca se sabe o que o outro aprende, colocando a educação como campo vinculado ao caos, ao risco e ao imponderável.

Momentos de ações são capturados nas imagens, que se adensam em proposições híbridas de cores, de luz e de sombras. As fotos compõem planos de experimentação com a matéria, com a textura, com o visível que se constituem nas intersecções destes elementos ativos presentes nas fotos. Ativos já que atuam como forças a produzirem variações nas imagens fixas do pensamento que tendem a sedentarizar signos urbanos, femininos e íntimos.

A educação, como foco neste artigo, é pensada como prática cognitiva de invenção de novos reais, novas cidades e subjetivações. Esses processos inventivos de si e do mundo estão ligados às relações com o tempo e a matéria. Entendendo o tempo como tendência à criação e a matéria como tendência à repetição, a invenção de novas formas cognitivas acontece nos interstícios dessas duas tendências presentes.
Frente a isto, as imagens apresentadas apontam alguns reconhecimentos com as ruas, as roupas, os varais, as mulheres, as janelas, os baldes; e também conexões que fazem os sentidos variarem como as instalações de varais de roupas penduradas nas ruas, mulheres com casacos masculinos a lavarem roupas sujas, ao lado de fotos antigas de muIheres lavando roupas em contextos bucólicos e compondo com uma casa abandonada cheia de roupas que povoam suas paredes e tetos, com corpos-mulheres vestidos jogados em janelas.

Nessas relações entre tempo e matéria, o processo educativo acontece diante da exigência de um paradoxo que tende à criação que se vincula ao tempo. A criação está ligada ao tempo, e só se efetivará como produto das forças criadoras através das tensões permanentes com a matéria. Assim, criação e repetição vivem em estado de captura mútua, sendo que a criação só se efetiva em processo inventivo na conexão entre tempo e matéria.

As imagens em intervenção urbana das ações Ghawazee entram em contato com a matéria através de olhares táteis das ações práticas e diretas, aliando-se às tendências criativas na matéria, criando um contato inventivo na experimentação da cidade via imagem, que se efetiva quando há uma permissão de contágio com tais problematizações ao nos colocarmos em relações com tais imagens.

Bergson (1979b) fala da "intuição" como uma capacidade corporal e sensorial de captação do real que apresenta um caráter fugidio e se articula ao presente. Nesse sentido, encontra-se à margem do controle tal qual ele se estabeleceu como vontade na modernidade. A intuição encontra-se, assim, vinculada ao intempestivo no presente e à duração como invenção e mobilização da vida. 
A partir da perspectiva bergsoniana, a intuição é tomada como mobilizadora da vida e funciona como ferramenta articulando imagens, performance e cidade em relação à invenção de novos problemas frente ao cotidiano da cidade e a própria relação com as imagens. O presente apresenta na duração modos de ser do real em processos de elaboração contínua do novo e da criação de outras formas de experimentar o urbano das imagens. A inventividade agenciada pelas fotografias atua na cognição como prática e coloca em relações componentes heterogêneos do urbano.

Nesse processo, a intuição, como ferramenta para abordagem das imagens, funciona como "tendência crítica", que, segundo Bergson, seria a capacidade de apreender o tempo e colocar problemas à inteligência ${ }^{10}$.

Há traços virtualmente presentes de um no outro, inteligência e intuição co-existem no processo cognitivo. As imagens em relações diretas com os objetos e a matéria engendram um tempo e criam uma realidade que só ganha existência nas relações com as imagens e, concomitantemente, perfura o que se poderia representar da cidade, dos corpos e das intimidades.

A invenção se faz na dimensão prática de experimentação como condição de constituição tanto das subjetividades e da cognição, quanto do mundo (KASTRUP, 2007). A cognição como invenção se faz na abertura para o novo, o inesperado, o imprevisível. Esse procedimento de abertura se dá com a potência de formular problemas, como função de problematização do mundo.

\footnotetext{
$\overline{10}$ Bergson (1979a) faz uma diferenciação entre inteligência e intuição, sendo a primeira um processo de recognição do mundo ligado à representação e a segunda a própria invenção do mundo, vinculada à tendência crítica e à proliferação da vida. Ambas co-existem em estado de mistura, mesmo sendo de diferentes naturezas.
}

Nesse sentido, a educação atua como campo a ser problematizado nas imagens tomadas como representação do momento, dissolvendo distanciamentos com relação à cidade, aos corpos, às ações performativas e à produção estética da vida; ou seja, produzir uma educação como invenção da vida vinculada às instabilidades, agenciadas pelas imagens apresentadas como analisadoras que mobilizam as organizações rígidas dos modos de abordar as imagens como representação, aliando-se às forças intempestivas de um tempo inventivo.

Blocos de imagens articulam-se a uma perspectiva de educação ligada a uma cognição inventiva, que problematiza o mundo. Assim, não está pré-ocupada com soluções de problemas já colocados, mas com sua invenção de problemas e construção de linhas de soluções provisórias e finitas, já que se trata da vida como campo híbrido e multirrelacional. A cognição é pensada como movimento da própria vida, como multiplicidade heterogênea que procura intervir e ativar linhas de fuga em combates ativos frente às capturas de lógicas impostas na relação com as imagens estritamente enquanto representação e recognição do mundo.

Deleuze (1956) também discorre sobre as relações de tempo e matéria, sendo que ambas se constituem como tendências que co-existem na realidade. Os sistemas vivos existem como tempo e matéria, mas com preponderância do tempo inventivo de si e das relações com o mundo. O tempo como tendência à invenção agencia diferenciações e divergências, criação de híbridos. Assim, as imagens articulam zonas de bifurcações engendrando tempos na matéria, instabilidades criativas na repetição e agenciando sistemas vivos ao criarem novos modos de existir nas conexões com o urbano das imagens. 
Diante disso, as imagens, ao operarem, produzem uma zona de bifurcação, de explicitação de híbridos e de crítica às tentativas de invariabilidades da imagem e do cotidiano urbano, derivando assim processos educativos no e do mundo.

Pensar a invenção como proliferação da vida é vincular-se ao tempo como criação, como movente, como instável. Nesse sentido, o presente carrega pontos de instabilidade e se abre às desestabilizações. As imagens acontecem no presente da obra com aberturas a criarem instabilidades e a sofrerem os efeitos instáveis do tempo presente, como a ocorrência de luz, de vultos, de sombra, de ângulos. O presente apresenta-se como material de criação para as imagens fotográficas e o presente como duração é considerado como componente da obra para a imagem.

As imagens, do modo como a tomamos, não se configuram como um campo de representação no sentido de aquisição técnica do real mimetizado na imagem, assim como, o aprender não se efetua enquanto acúmulo de informações e formatação dos corpos, das atuações e dos movimentos. No trabalho com as imagens, essas se abrem à duração de um presente que se apresenta na relação com a própria imagem, e o próprio trabalho com as imagens exige a criação de conexões com os blocos de sensações que as imagens agenciam nos corpos, fazendo notar os pontos de maior tensão ao criarem essas conexões e entrarem em composição com alguma coisa no que acontece na relação entre imagem e corpo, sendo esses os pontos de bifurcação que vão promover afetos da produção estética vinculada ao presente e aos acontecimentos.

Apostamos em potências educativas disparadas nas imagens, que estão na abertura ao que seria uma falha, um desvio, que, em fun- ção da vinculação com o presente, exprime-se como acontecimento e engendra outros modos de existência, outras conexões, remanejando a própria proposta imagética e vinculando-a à imanência instável da vida. Nesse sentido, experimentar o real da imagem é produzir nos corpos essa abertura à errância, à experimentação, à porosidade. No sentido aqui colocado, esse estado errante da imagem é gerado nessa ligação com o presente, como um exercício para habitar um tempo descontínuo e propiciar aos signos e aos objetos entrarem em derivas.

\section{Imagens em deriva}

Os signos e a cidade entram em derivas frente aos signos da arte, com imagens que disparam outras cidades e outros contextos possíveis de um mundo urbano. Para falar em deriva encontro-me com o texto intitulado "Causas e razões das ilhas desertas" de Gilles Deleuze ${ }^{11}$.

O homem se aventura no mar e pode se deparar com ilhas desertas, podendo habitá-las. O homem se separa do continente, coloca-se distante, sozinho e perdido. Dessa forma, é preciso empreender uma prática quando se está separado, mas a própria separação é condição para se recriar; assim, criação e separação estão juntas no processo de habitação das ilhas.

Ao nos depararmos com imagens ocupadas por varais com roupas sendo batidas por mulheres vestidas em ternos executivos, com texturas do urbano molhado em roupas que interditam possíveis fluxos automotivos, somos levados a inventar outras cidades. Em imagens de corpos partidos e jogados em composições

\footnotetext{
11 Texto da década de 1950 publicado no Brasil em um compêndio de textos e entrevistas chamado "A Ilha Deserta e outros escritos", edição preparada por David Lapoujade e organizada por Luiz B. L. Orlandi em 2006.
} 
transversais, roupas e corpos subindo as janelas, as paredes, o teto, o chão. Novos corpos, casas, ruas se criam em imagens que problematizam os próprios corpos, as ruas, as casas, as ações cotidianas. Imagens que entram em conexões com o caos do pensamento, com a experimentação e com a problematização do mundo, ligando-se de forma política a uma educação outra.

O autor apresenta a personagem do náufrago como aquele que precisa estar à deriva para encontrar a ilha deserta e, dessa forma, o movimento do homem em direção à ilha retoma o movimento da formação, da criação da própria ilha. O homem que habita a ilha deserta precisa realmente recriar o próprio movimento de formação inicial dessa, caso contrário, ele entrará na ilha, mas não a habitará. Ele fará dela um simples prolongamento do continente, ou um novo lugar para o mesmo homem continental. Ao entrar em relação com as imagens como criação de um real, os signos preconcebidos do urbano das imagens e dos processos de subjetivação a elas vinculados entram em deriva, reinventando o movimento de visibilidade frente à textura das fotos, criando aberturas para habitarem ilhas desertas antes inexistentes.

O náufrago, ao aportar-se na ilha, revela que não é apenas a ilha que se separou do continente, mas é o homem, que ao estar na ilha, se separou do mundo. Coloca que não é apenas a ilha que se cria do fundo através do mar, mas o homem também recria o mundo partindo da ilha e sobre as águas, podendo criar uma ilha original, mesmo estando em uma ilha derivada e vice-versa. Imagens entram em estados-ilhas e vivemos o risco de, como náufrago, encontrar ilhas desertas, reais ainda invisíveis ao entrarmos em deriva com as imagens. Imagens-ilhas que rasgam o urba- no para entrar em derivas e se separaram do mundo, tendo como potencialidade a recriação do próprio real da imagem.

Deleuze nos alerta que a ilha pode ser ocupada por homens que trazem o continente consigo e a invadem, fazendo-a entrar em desacordo com o estado de deserta. Esse tipo de ocupação povoa a ilha fazendo dela uma extensão do continente, mas não consegue habitá-la. Imagens podem ser visitadas como representação de mundo, como um mero meio para se acessar um real anterior à imagem com um fundamento no mundo objetal, desarticulando o campo político que existe na imagem enquanto criação de um real que só se efetiva na imagem. Assim, as imagens passam a ser extensões do continente predefinido, apenas atingindo dimensões recognitivas; não há deriva, não há náufrago, não se habita a ilha deserta.

Dessa forma, mesmo os homens dispostos a estarem na ilha, precisam estar dispostos a serem idênticos ao movimento que os coloca na ilha, em composição com o impulso que produziu a ilha; caso contrário, estarão sempre de fora e não habitarão a ilha deserta. Para se habitar a ilha deserta, é necessário que o homem entre em deriva, preparado para recriar o mundo agenciado por imagens que derivam do mundo, e inventam um novo real.

Diante do exposto, o autor finaliza seu texto afirmando que a criação e o começo não provêm da ilha deserta, mas sim a re-criação e o re-começo, pois a criação e o começo vêm do mundo, do continente. A partir da ilha deserta tudo recomeça, ela é o mínimo necessário para se reinventar o mundo, o material que sobrevive do próprio mundo e deve ser o bastante, nem mais nem menos, para se produzir novamente um mundo. Imagens como ilhas desertas precisam assim de um habitante disposto 
a entrar nas derivas que essas agenciam ao reinventar signos e considerar os contornos produzidos pela luz e sombra como um mínimo de restos de mundo necessários para que o real se reinvente na imagem.

Diante do que apresentamos neste texto, propomo-nos um exercício de pensar o real da imagem, entrando em campos experimentais de coisas que se agenciam nas imagens, campo de pensamento ligado ao caos do que pode a imagem, campo inventivo de si e do mundo. Buscamos dobras das imagens no urbano, nos corpos, na ação performática. O mundo que é criado ao entrar em deriva, ao encontrarmos imagens como ilhas desertas que temos a abertura de habitar. Assim se dá um exercício.

Varais interditam os trajetos cotidianos e desarticulam os fluxos da cidade. Roupas sujas lavadas em público colocam intimidades a secar. Exposições úmidas de roupas lavadas na tentativa de limparem rastros de lembranças dos encontros. Limpeza de cheiros, suores, poeira, manchas. Bate, esfrega, enxagua roupas, lembranças, imaginações de tempos. Baldes e varais colorem o concreto e desobstruem movimentos pré-estabelecidos marcados em trajetos óbvios de trânsitos urbanos.

As roupas penduradas escorrem tintas incolores que criam desenhos no asfalto. Sulcos abrem brechas de novos cotidianos e param os trânsitos em ruas largas. Asfaltos se quebram entre varais, roupas e marcas d'água. Novas ruas se formam, novos trânsitos se anunciam e encontram outros trajetos.

Mulheres fazem do tanque um lago, saias, olhares, sorrisos femininos friccionam tecidos e sabão. Escorrem líquidos que turvam a água em pose para foto. Texturas de imagens enveIhecidas lembram tempos de mulheres lavadeiras no entorno da grande bacia a esfregar.

Lagos de água dão lugar a montes de roupas na próxima imagem com mulheres ao redor a pegar a roupa suja. Mulheres surpeendem nosso olhar transvestidas em ternos masculinos a trabalharem. Roupas sujas e íntimas empilhadas no meio da rua bloqueiam possíveis saídas dos automóveis estacionados. As mulheres trabalham tranquilamente a separarem, lavarem, empilharem roupas com vestimentas executivas em labor doméstico.

Roupas se espraiam, sobem, invadem e trepam, copulam em ruas e casas vazias. Tecidos preenchem cômodos vagos, movimentam e desenham paredes, chão e tetos. Se espaIham, entram e saem pela janela. Caídas, jogadas, abandonadas, amassadas em casas desabitadas, velhas, descascadas, empoeiradas.

Corpos e roupas jogados, largados, espaIhados em janelas e escombros de casas em decomposição. Abandono de mulheres, tecidos e construção. Vidas em risco. 


\section{Referências}

BERGSON, H. A evolução criadora. Coleção Os Pensadores (p. 153-205). São Paulo: Abril Cultural, 1979a.

O pensamento e o movente: introdução. Coleção Os pensadores (p. 99-151). São Paulo: Abril Cultural, 1979b.

Memória e Vida: textos escolhidos por Gilles Deleuze. Trad. Bento Prado Neto. 2. ed. São Paulo: Editora WMF Martins Fontes, 2011.

A fala cotidiana. In: BLANCHOT, M. A conversa infinita 2: a experiência limite. São Paulo: Escuta, 2007.

DELEUZE, G. A ilha deserta e outros escritos. Edição preparada por David Lapoujade, organização e edição Luiz B. L. Orlandi, São Paulo: Iluminuras, 2006.

Conversações. Trad. Peter Pál Pelbart. São Paulo: Ed. 34, 1992.

Diferença e repetição. Trad. Luiz Orlandi e Roberto Machado. Rio de Janeiro: Graal, 1988.

Proust e os signos. Trad. Antonio Carlos Piquet e Roberto Machado. Rio de Janeiro: Forense-Universitária, 1987.

. La Conception de la Différence chez Bergson. In: Les Études Bergsoniennes, vol. 4, Paris, Albin Michel, 1956.

DELEUZE, G.; PARNET, C. Diálogos. Trad. Eloisa Araújo Ribeiro. São Paulo: editora Escuta, 1998.

DELEUZE, G.; GUATTARI, F. Mil Platôs: capitalismo e esquizofrenia. V. 4. Trad. Suely Rolnik. São Paulo: Ed.34, 1997.

; . Mil Platôs: Capitalismo e Esquizofrenia. V. 1. Trad. Aurélio Guerra Neto e Célia Pinto Costa. Rio de Janeiro: 34, 1995.

; . O que é a Filosofia? Trad. Bento Prado Jr. e Alberto Alonzo Muñoz. Rio de Janeiro:

Ed.34, 1992.

DUSCHATZKY, S. Maestros Errantes: experimentaciones sociales en la intempérie, Buenos Aires, Paidós, 2007. 
GUATTARI, F. Da produção de subjetividade. In: PARENTE, A. (Org.) Imagem Máquina: a era das tecnologias do virtual. Rio de Janeiro: Editora 34, 1993.

Caosmose: um novo paradigma estético. Trad. Oliveira, A. L.; Leão, L. C. São Paulo: 34, 1992.

KASTRUP, V. A intenção de si e do mundo: uma introdução do tempo e do coletivo no estudo da cognição. Belo Horizonte: Autêntica, 2007.

PARENTE, A. (Org.) Imagem Máquina: a era das tecnologias do virtual. Rio de Janeiro: Editora 34, 1993.

PEIXOTO, N. B. Passagens da imagem: pintura, fotografia, cinema, arquitetura. In: PARENTE, A. (Org.) Imagem Máquina: a era das tecnologias do virtual. Rio de Janeiro: Editora 34, 1993.

Submetido para avaliação em 01 de maio de 2012.

Aprovado para publicação em 18 de outubro de 2013.

Juliana Soares Bom-Tempo: Pesquisadora Doutoranda da Universidade Estadual de Campinas - Campinas - SP

- Brasil. E-mail: ju_bomtempo@yahoo.com.br 